\title{
Analysis of the Impact of Three Phthalates on the Freshwater Gastropod Physella Acuta at the Transcriptional Level
}

\author{
Marina Prieto-Amador \\ National University of Distance Education \\ Patricia Caballero \\ National University of Distance Education \\ Jose-Luis Martinez-Guitarte ( $\nabla$ jlmartinez@ccia.uned.es ) \\ National University of Distance Education
}

Research Article

Keywords: Invertebrates, aquatic toxicology, plasticizers, gene expression array

Posted Date: February 1st, 2021

DOI: https://doi.org/10.21203/rs.3.rs-154303/v1

License: (c) (1) This work is licensed under a Creative Commons Attribution 4.0 International License. Read Full License 


\section{Abstract}

Plastic pollution is one of the leading environmental problems. Phthalates are widely used plastic additives released into the environment. Although the phthalates' effects have been extensively studied on vertebrates, there is a gap in knowledge on their effects on invertebrates. This work analyzes the impact of three phthalates, diethyl phthalate (DEP), benzyl butyl phthalate (BBP), and bis-(2ethylhexyl) phthalate (DEHP), on the gastropod Physella acuta at the molecular level to establish the putative pathways involved in its response to them. By real-time PCR, we obtained the expression profile of thirty genes in one-week exposed animals at $0.1,10$, and 1000 $\mu \mathrm{g} / \mathrm{L}$. The genes cover the DNA repairing mechanism, detoxification mechanisms, apoptosis, oxidative and stress responses, immunity, energy reserves, and lipid transport. The results show that while DEP and DEHP did not cause alteration of the mRNA levels, BBP modulates almost all the genes tested. It can be concluded that the impact of BBP is extensive at the molecular level. However, it cannot be dismissed that the increase in transcriptional activity is a general response due to this compound's well-known role as an endocrine disruptor. Additional research is needed to elucidate the differences observed in the impact of these compounds on this gastropod.

\section{Introduction}

Plastics are incredibly versatile materials useful for a wide range of applications. However, plastic production is under the scope of green policies to reduce the pollution of the environment. The two main processes used to produce plastics are polymerization and polycondensation, requiring specific catalysts and other additives. It has been estimated that 8300 million metric tons (Mt) of virgin plastics were produced in 2017. In 2015, approximately 6300 Mt of plastic waste were generated, with $79 \%$ accumulated in landfills or the natural environment ${ }^{1}$. Phthalates are esters of phthalic anhydride mainly used as plasticizers to increase the flexibility, transparency, durability, and longevity of plastics, mainly to soften polyvinyl chloride (PVC). As the phthalate plasticizers are not chemically bound to PVC, they can leach, migrate, or evaporate into indoor air and atmosphere, foodstuff, and other materials. The worldwide production of phthalates increased from 2.7 to nearly 6 million tons per year during the decade of 2007-20172, being now-ubiquitous environmental contaminants. They are released regularly from the containing products ${ }^{2,3}$, and reach almost all the environment's compartments ${ }^{4}$. In German rivers, phthalates have been found in the range from 0.33 to $97.8 \mu \mathrm{g} / \mathrm{L}$ for bis-(2-ethylhexyl) phthalate (DHEP) and from 0.12 to $8.80 \mu \mathrm{g} / \mathrm{L}$ for dibutyl phthalate (DBP), while concentrations in sediment were from 0.21 to $8.44 \mu \mathrm{g} / \mathrm{kg} \mathrm{dw}$ of DEHP and 0.06 to $2.08 \mu \mathrm{g} / \mathrm{kg}$ $\mathrm{dw}$ for $\mathrm{DBP}^{5}$. A more recent study found different phthalates in varying ranges in the Ganga river, such as dimethyl phthalate (DMP) $0.03-$ $0.05 \mu \mathrm{g} / \mathrm{L}$, diethyl phthalate (DEP) $0.04-2.14 \mu \mathrm{g} / \mathrm{L}$, di-n-butyl phthalate (DnBP) non detected (ND) $-2.27 \mu \mathrm{g} / \mathrm{L}$, benzyl butyl phthalate

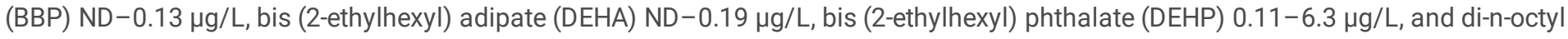
phthalate (DnOP) ND-0.05 $\mu \mathrm{g} / \mathrm{L}^{6}$.

The impact of phthalates on the environment has been studied in the last few years, focusing mainly on vertebrates. It is known that phthalates act as endocrine-disrupting chemicals (EDCs), producing severe health effects ${ }^{7-11}$ and even having a long-term impact on the epigenome ${ }^{12}$. Phthalates can alter an animal's metabolism, but there is still a lack of information about their effects on invertebrates. Although the studies often include analysis at the molecular level ${ }^{13-15}$, the invertebrates' diversity demands additional studies involving other species and groups. One of the groups that has been poorly studied, especially in freshwater representatives, is the mollusk. Most of the studies focus on marine species, and the molecular analysis in freshwater species is basically absent. Furthermore, in gastropods, the studies are centered on the marine representative Haliotis diversicolor ${ }^{16-18}$. The freshwater snail Physella acuta (Draparnaud, 1805), also known as Physa acuta, belongs to the Physidae family. It is a cosmopolitan species living in lakes and ponds. It is easily cultured, so it could be a good representative of gastropods to assess the compounds' toxicity.

Toxicants can alter different physiological processes, such as growth and reproduction, reaching the effects by working in lower complexity levels such as the molecular and cellular processes. Therefore, it is essential to get information about the mode of action to define a compound's impact on an animal. The changes in mRNA levels of genes are useful tools to detect the putative pathways altered by a chemical, providing a picture of the damage that it can cause. Recently, we obtained the transcriptome of Physella acuta and identified genes to analyze the toxicity of the fungicide vinclozolin ${ }^{19}$. Taking advantage of the transcriptome and sequences in the database, we have identified new genes to study several pathways involved in response to phthalates. The genes are related to DNA repairing mechanisms, detoxification mechanisms (phase I, phase II, and phase III), oxidative stress, stress response, immunity, epigenetics, lipid transport, and energy reserve metabolism.

This work aims to offer some light on the impact, at the molecular level, that phthalates have on the gastropod Physella acuta. Twomonth-old adult snails were exposed for one week to three phthalates, diethyl phthalate, benzyl butyl phthalate, and bis-(2-ethylhexyl) 
phthalate. The gene expression profile of thirty genes was obtained for the first time in response to these compounds, which is a first step to assess the damage they can produce in a freshwater invertebrate that is pivotal on the food web of freshwater ecosystems.

\section{Results}

\section{Gene identification}

Eighteen genes were identified for the first time in this work for $P$. acuta (Table 1, Fig. 1). They all showed homology with genes in the database, mainly with those described in the freshwater snail Biomphalaria glabrata. In some of the genes, the homology was with Aplysia californica and Aplysia kurodai, and only one had homology with a gene of the marine bivalve Mytilus coruscus. The genes covered different pathways. Two of the genes coded for proteins homologous to RAD21 and RAD50 involved in repairing of DNA damage 20,21 . There were two other oxidative-stress-related genes, which code for catalase and Mn superoxide dismutase, enzymes involved in removing free radicals ${ }^{22}$. One of the sequences coded for acetylcholinesterase, an enzyme involved in nerve impulse transmission. The other genes coded for proteins related to apoptosis (AIF3, apoptosis inducible factor 3), stress (sHSP 17.9, small heat shock protein 17.9; Hsc70 (4), heat shock protein cognate 70 - 4; HIF-1a, hypoxia-inducible factor 1 a), histone modification (HDAC1, histone deacetylase 1; KATB6, histone acetyltransferase KAT6B), DNA methylation (DNMT1, DNA methyltransferase 1), immune system (ApA, L-amino acid oxidase Aplysianin-A), one cytochrome P450 (cyp72a15), energy reserves (PYGL, glycogen phosphorylase), and lipid transport (ORP8, oxysterol-binding protein-related protein 8).

Table 1

Accession numbers and homologies of the newly identified genes in Physella acuta

\begin{tabular}{|c|c|c|c|c|}
\hline $\begin{array}{l}\text { Accession } \\
\text { number }\end{array}$ & Gene & $\begin{array}{l}\text { ORF size } \\
\text { (aa) }\end{array}$ & Similarity & $\begin{array}{l}\text { Identity- } \\
\text { Homology }\end{array}$ \\
\hline MW456925 & $\operatorname{rad} 21$ & 678 & $\begin{array}{l}\text { PREDICTED: double-strand-break repair protein rad21 homolog - } \\
\text { Biomphalaria glabrata }\end{array}$ & $85 \%-92 \%$ \\
\hline MW456929 & $\operatorname{rad} 50$ & 1200 & PREDICTED: DNA repair protein RAD50-like - Biomphalaria glabrata & $68 \%-84 \%$ \\
\hline MW456922 & AChE & 548 & PREDICTED: cholinesterase 1-like - Biomphalaria glabrata & $56 \%-69 \%$ \\
\hline MW456920 & Catalase & 508 & PREDICTED: catalase-like - Biomphalaria glabrata & $82 \%-90 \%$ \\
\hline MW456928 & AlF3 & 591 & PREDICTED: apoptosis-inducing factor 3-like - Biomphalaria glabrata & $77 \%-88 \%$ \\
\hline MW456924 & Сyp72a15 & 486 & cytochrome P450 72A15 - Aplysia californica & $68 \%-82 \%$ \\
\hline MW456930 & DNMT1 & 212 & DNA methyltransferase 1, partial - Aplysia californica & $88 \%-91 \%$ \\
\hline MW456923 & KAT6B & 1277 & $\begin{array}{l}\text { PREDICTED: histone acetyltransferase KAT6B-like - Biomphalaria } \\
\text { glabrata }\end{array}$ & $49 \%-62 \%$ \\
\hline MW456919 & HDAC1 & 527 & probable histone deacetylase 1-B - Aplysia californica & $88 \%-94 \%$ \\
\hline MW456918 & sHSP17.9 & 159 & PREDICTED: heat shock protein Hsp-12.2-like - Biomphalaria glabrata & $52 \%-71 \%$ \\
\hline MW456926 & ApA & 522 & Aplysianin-A; Precursor - Aplysia kurodai & $45 \%-65 \%$ \\
\hline MW456921, & ORP8 & 955 & $\begin{array}{l}\text { PREDICTED: oxysterol-binding protein-related protein 8-like - } \\
\text { Biomphalaria glabrata }\end{array}$ & $74 \%-83 \%$ \\
\hline MW456927 & PFKFB2 & 234 & $\begin{array}{l}\text { PREDICTED: 6-phosphofructo-2-kinase/fructose-2,6-bisphosphatase- } \\
\text { like - Biomphalaria glabrata }\end{array}$ & $84 \%-89 \%$ \\
\hline \multirow{5}{*}{$\begin{array}{l}\text { Suplementary } \\
\text { material }\end{array}$} & SOD Mn & 219 & superoxide dismutase - Mn, mitochondrial-like - Biomphalaria glabrata & $80 \%-88 \%$ \\
\hline & Hsc70-4 & 648 & $\begin{array}{l}\text { PREDICTED: heat shock } 70 \text { kDa protein cognate } 4 \text { - Biomphalaria } \\
\text { glabrata }\end{array}$ & $98 \%-98 \%$ \\
\hline & HIF1a & 716 & $\begin{array}{l}\text { PREDICTED: hypoxia-inducible factor 1-alpha-like, partial - } \\
\text { Biomphalaria glabrata }\end{array}$ & $64 \%-73 \%$ \\
\hline & PYGL & 847 & glycogen phosphorylase, brain form - Aplysia californica & $89 \%-97 \%$ \\
\hline & ACTB_G1 & 376 & ACTB_G1 - Mytilus coruscus & $99 \%-100 \%$ \\
\hline
\end{tabular}


The adult snails were exposed for one week to each phthalate. The mRNA analysis showed that DEP and DEHP did not modify the mRNA quantity of any of the genes and the concentrations tested (Figs. 2-6). However, the BBP was strikingly very effective and altered almost all the genes tested but with some differences. It is worth clarifying that statistical analysis without Bonferroni correction rendered significant differences for all the BBP treatments in all genes except for the higher concentration in GSTm1. However, applying Bonferroni's correction, the results showed that for rad21, AChE, SOD CuZn, SOD Mn, Casp3, AIF3, Cyp2u1, Cyp3a7, Cyp72a15, GSTk1, HDAC1, sHSP17.9, HSP60, Grp78, HSP90, HIF1a, APA, PYGL, and ORP8, there was an increase of transcriptional activity at all the concentrations tested. Although there is an increasing trend in the rest of the genes, some results did not show a statistical significance to be considered different from the control. The genes which showed statistical significance for the two lower concentrations but not at the highest were rad50, DNMT1, KAT6B, SHSP16.6, and HSC70.4 (Figs. 2, 5, and 6). Cat and Cyp4f22 were altered for the concentration of 1 $\mu \mathrm{g} / \mathrm{L}$ but not for the other two (Figs. 2 and 3). MRP1/ABCC1 mRNA levels were increased for 1 and $100 \mu \mathrm{g} / \mathrm{L}$, while GSTo1 and GSTt2 were significantly upregulated for $0.01 \mu \mathrm{g} / \mathrm{L}$ only (Fig. 4). Finally, GSTm1 did not show statistically significant alterations, although a trend to have a higher mean than the control can be observed (Fig. 4).

\section{Discussion}

The development of massive sequencing has provided a relatively cheap method to obtain the transcriptome of a species. Taking advantage of it, we have used a previously obtained transcriptome to identify eighteen genes related to different pathways of interest in ecotoxicology. With others yet described, the genes identified allow us to analyze these pathways' response to different chemicals. The genes identified cover processes of interest in ecotoxicology such as DNA repair mechanisms, stress, detoxification, apoptosis, immunity, energy reserves, and lipid transportation. There is a growing interest in combining ecologically relevant endpoints with biochemical and molecular parameters to seek a more integrative analysis. In this sense, to increase the number of genes described will allow for the design of standard arrays that could be used in combination with toxicity tests. In this way, initiatives such as the Adverse Outcome Pathway wiki ${ }^{23}$ will increase its relevance in assessing old and new compounds and provide putative mechanisms of action to explain the differences to the animals' specific physiology. Furthermore, increasing knowledge at the molecular level in this species supports its use as a representative of freshwater gastropods in toxicity analysis. There is a lack of model organisms in freshwater mollusk, being one of the animal groups whose pollution response is currently less known.

The eighteen genes evaluated in this work show homology with those previously described in other species, as expected. Rad21 and rad50 are both genes involved in DNA repairing mechanisms. The first one is an essential gene encoding a DNA double-strand break (DSB) repair protein ${ }^{20}$. In contrast, the second is a member of the protein complex MRN (including Mre11, Rad50, and Nbs1) that functions in DNA double-strand break repair to recognize and process DNA ends as well as a signal for cell cycle arrest ${ }^{24}$. Practically, there is no information about these genes in mollusks, with only one report in Carssostrea gigas for rad $50^{25}$. The relevance of these genes is that they can be combined with other methodologies, such as the comet assay, to perform an integrated study to know if a compound is genotoxic and if the organism has the ability to compensate for the damage.

The catalase and the Mn superoxide dismutase genes allow us to analyze the impact of oxidative stress. Usually, oxidative stress analysis is focused on biochemical parameters, such as the enzyme's activity. However, it should also include a transcriptional activity study since it can provide additional information about the mid- and long-term response. The protein turnover can also be relevant in the response, especially in chronic exposure to toxicants. It is similar to that concerning detoxification mechanisms. The GST activity is one of the most used methods to assess detoxification ${ }^{26}$, but it does not differentiate between the members involved. A similar situation is found with the cytochromes P450, which show high diversity with many roles in the cell ${ }^{27}$. The Cyp72a15 gene increases the number of Cyp450s described in $P$. acuta and helps to elucidate how the organism can process the toxicants.

The small heat shock gene and the heat shock cognate gene extend the battery of genes available to assess this species' stress response. The small heat shock gene is difficult to match with other species' genes because the alpha-crystallin domain characterizes them, but there is no other sequence that, presently, allows for the homology to be established. Additional functional studies will help search for it. However, it is worth mentioning that HIF $1 a$ offers a new aspect of stress related to hypoxia ${ }^{28}$. The stress response is mainly focused on the canonical heat shock proteins, so other mechanisms involved in specific stresses, such as hypoxia, usually are neglected. The description of the factor inducible by low oxygen levels will help to know the effect of the toxicant on oxygen intake.

Similarly, the rest of the genes identified allow for the analysis of additional pathways that can also be altered by toxicants, like apoptosis (AIF3), the immune system (ApA), energy reserves (PYGL), and lipid transport (ORP8). To our knowledge, these genes are analyzed for the first time concerning pollution in freshwater mollusks. The last three genes, DNMT1, KATB6, and HDAC1, are involved in epigenetic 
mechanisms. Epigenetic regulation is arising as one of the long-term effects of toxicants. However, the genes involved in invertebrates are still poorly represented in toxicity analysis. The description of these three genes opens the possibility of analyzing their role in the epigenetic response and the relevance that they have in the transgenerational effects that have started to be described with different toxicants $29-31$.

Plastics in the environment are a growing problem that involves the release of polymers themselves and the compounds used as catalysts and additives during the degradation process. Phthalates are such additives that are increasing their presence in the environment $5,32,33$. Three phthalates, BBP, DEP, and DEHP, have been analyzed in this work, which showed a differential impact in Physella acuta. Two of the compounds, DEP and DEHP, did not show any change in the genes' mRNA levels. It has been described previously that both phthalates can alter the physiology of invertebrates ${ }^{15,34-37}$, including mollusks ${ }^{38-40}$. The differences observed here can be assigned to the type of analysis (molecular vs. physiological), the exposure time (one week vs. a few hours or days), the concentration used ( $\mu \mathrm{g} / \mathrm{L}$ vs. $\mathrm{mg} / \mathrm{L}$ ), and evidently, the species used. Additional research will help elucidate the putative relationship between the different data obtained and those from other organisms. However, it is essential to highlight that the obtained results suggest that Physella acuta can manage the environmentally relevant doses used in this work for DEP and DEHP. This species may be less sensitive to these phthalates, but this eventually will require further research, including the use of other methodological approaches, to confirm it.

On the other hand, BBP showed a very different picture, with almost all genes increasing the mRNA levels in response to the compound. Previous studies in other organisms have confirmed that BBP can induce different types of damage such as apoptosis ${ }^{41}$, genotoxicity 42 , oxidative stress ${ }^{43}$, stress response activation ${ }^{44}$, or endocrine disruption ${ }^{13}$. Although there are studies in invertebrates showing the impact on development and other physiological processes ${ }^{38,45}$, most of them did not focus on the putative mode of action, with only a few of them trying to delve into the mechanisms of response. BBP can affect very diverse processes in the organisms, and here we have found that all the pathways analyzed are modulated. The results can be considered in two ways. The first is that the changes are reflecting specific alterations on these pathways. It would mean that BBP is the most active phthalate in $P$. acuta, with a broad spectrum of action and a potential activity on many pathways. The second possibility is that BBP induces some change in other non-tested processes, like the hormonal system, that increases the transcriptional rate of the genes because of its regulatory role in the cell. It is relevant to keep in mind its known role as an endocrine disruptor of BBP46. However, a recent study in Daphnia magna can help elucidate between both possibilities since, by RNA-Seq, it has been observed that genes involved in signal transduction, cell communication, and embryonic development were significantly down-regulated, while those related to biosynthesis, metabolism, cell homeostasis, redox homeostasis were remarkably upregulated upon BBP exposure ${ }^{47}$. Although the organism and the stage analyzed are different than in our study, those results support the idea that BBP can have multiple effects on the cell metabolism, altering the pathways analyzed.

It is also essential to consider that most of the studies on invertebrates that involve transcriptional activity analysis use short exposure times and use arthropods ${ }^{13,44,47}$. Limited data are available on mollusks and, usually, they are on the marine representatives ${ }^{39,46}$. To our knowledge, this is the first study on a freshwater snail that shows that BBP can produce a substantial effect on cell metabolism. Several of the altered pathways can explain, in some way, the effects observed in other organisms, like the DNA repairing mechanisms, which are related to DNA damage, or the alteration of the genes involved in histone and DNA modification, which are related to epigenetic regulation. However, other genes open new possibilities, such as $A p A$ and $O R P 8$, involved in pathways not studied in other organisms. The changes in genes involved in oxidative stress, stress response, and detoxification back previous analysis, adding new light about the mechanisms involved in modulating these processes. The absence of changes in GSTm1 supports a differential role for each GST family in response to toxicants. On the other hand, the differences concerning concentrations for some of the genes suggest subtle differences requiring additional kinetic analysis to elucidate early and late activated genes.

As stated before, the results obtained in this work show that DEP and DEHP have no apparent effect in a week exposure at environmentally relevant concentrations. However, BBP shows a strong effect in comparison. It could be due to several reasons that need to be explored in future works. One possibility is the structure of each compound. In this sense, BBP has two rings while DEP and DEHP have only one. This factor could determine the biological activity that they have. Another possibility is that DEP and DEHP have effects earlier than the time studied, and the cell returned to the basal state, being able to process and remove the compounds. Finally, it cannot be dismissed that DEP and DEHP are not toxic for $P$. acuta, at least at environmentally relevant concentrations. In any case, BBP can alter the metabolism of this species. Additional research should be done in $P$. acuta and other freshwater species to know the impact on organisms based on freshwater ecosystems' food web.

\section{Conclusions}


An analysis of the transcriptional activity of thirty genes in adults exposed to three phthalates has shown that DEP and DEHP have no apparent effect on the organism, so the mRNA levels were similar to those observed on controls. However, the third compound analyzed, BBP, strongly affects almost all the genes with an extensive action that alters DNA repairing, apoptosis, epigenetic regulation, stress response, immunity, and energy metabolism. BBP is toxic for $P$. acuta at the environmentally relevant concentrations used. However, additional research is needed to elucidate the kinetics of the response and how extent is it. Additional research is also required at different time points with DEP and DEHP to confirm that they cannot induce responses at the concentrations used. Finally, eighteen of the genes have been used for the first time to describe $P$. acuta. They increase the number of pathways that can be analyzed and support the use of this species in assessing toxicants in freshwater mollusks.

\section{Materials And Methods}

\section{Chemicals and reagents}

Diethyl phthalate 99.5\% (DEP), benzyl butyl phthalate 98\% (BBP), and bis-(2-ethylhexyl) phthalate 98\% (DEHP) were acquired from Sigma. Stock solutions for each compound were prepared for a concentration of $10.78 \mathrm{mg} / \mathrm{mL}$ BBP, $11.44 \mathrm{mg} / \mathrm{mL}$ DEP, and $965.3 \mathrm{mg} / \mathrm{ml}$ DEHP. The stock solutions were prepared in acetone for BBP and DEP, while DEHP was diluted in ethanol. Exposure solutions were prepared by 1:10,000 dilution of these stocks in the artificial pond water (see Treatment section below).

TRIzol and M-MLV enzyme were obtained from Invitrogen (Germany), oligonucleotide dT18 primer and gene-specific primers were supplied by Macrogen (Korea), RNase-free DNase was purchased from Sigma, DNA polymerase and dNTPs were obtained from Biotools (Spain), and EvaGreen was purchased from Biotium (USA).

\section{Animals}

The animals exposed were adults of the freshwater snail Physella acuta. The origin and the maintenance of the animals have been described previously ${ }^{48}$. The exposures were carried out in glass vessels filled with artificial pond water $\left(2 \mathrm{mM} \mathrm{CaCl}_{2}, 0.5 \mathrm{mM} \mathrm{MgSO}_{4}, 0.77\right.$ $\mathrm{mM} \mathrm{NaHCO}_{3}$, and $0.08 \mathrm{mM} \mathrm{KCl}$ ). The animals were fed twice a week, once with a 1:1 mixture of Sera Micron and Sera Shrimp Natural (Sera) and once with Sera Shrimp Natural.

\section{Treatment}

Each compound was tested in three concentrations, and six animals were exposed for each concentration and experiment. A glass vessel with $300 \mathrm{~mL}$ of artificial pond water was used for each concentration and compound; in the control, the same amount of solvent ( $30 \mu \mathrm{L})$ was added. The artificial pond water was replaced after three days, and the animals were fed with $20 \mathrm{mg}$ of Sera Shrimp Natural per recipient. The concentrations used were $0.1078 \mu \mathrm{g} / \mathrm{L}(0.345 \mathrm{nM}), 10.78 \mu \mathrm{g} / \mathrm{L}(34.5 \mathrm{nM})$, and $1078.0 \mu \mathrm{g} / \mathrm{L}(3.45 \mu \mathrm{M})$ for BBP; $0.1114 \mu \mathrm{g} / \mathrm{L}$ $(0.501 \mathrm{nM}), 11.14 \mu \mathrm{g} / \mathrm{L}(50.1 \mathrm{nM})$, and $1114.0 \mu \mathrm{g} / \mathrm{L}(5.01 \mu \mathrm{M})$ for DEP; and $0.0965 \mu \mathrm{g} / \mathrm{L}(0.247 \mathrm{nM}), 9.65 \mu \mathrm{g} / \mathrm{L}(24.7 \mathrm{nM})$, and $965.3 \mu \mathrm{g} / \mathrm{L}$ $(2.47 \mu \mathrm{M})$ for DEHP. Three experiments were performed for each compound, and the animals were exposed for seven days. At the end of the experiment, three of the animals were frozen in separate tubes for RNA extraction. The concentrations have been named as $0.1,10$, and $1000 \mu \mathrm{g} / \mathrm{L}$ to simplify the labeling in the figures.

\section{Gene identification}

Thirty-four genes were used. Sixteen have been previously described (Table 1) ${ }^{19,48}$. From the other eighteen, two are reference genes (actin beta/gamma 1 and 6-phosphofructo-2-kinase/fructose-2,6-bisphosphatase) while the other sixteen belong to DNA repairing mechanisms (Double-strand-break repair protein rad21, rad21; DNA repair protein rad50, rad50), nervous system (acetylcholinesterase, AChE), oxidative stress (catalase Cat, Mn superoxide dismutase, SOD Mn), apoptosis (apoptosis-inducing factor 3, AlF3), detoxification mechanisms (cytochrome P450 72A15, Cyp72a15), epigenetics (DNA methyltransferase 1, DNMT1; lysine acetyltransferase 6B, KAT6B; histone deacetylase 1B, HDAC1), stress response (sHeat shock protein 17.9, sHSP17.9; heat shock cognate protein 704 , Hsc70 (4), hypoxiainducible factor-1 alpha, HIF1a), immune system (Aplysianin-A, ApA), energy metabolism (Glycogen phosphorylase, $P Y G L$ ), and lipid transport (Oxysterol-binding protein-related protein 8, ORP8).

The sequences were obtained following the procedure described in Aquilino et al. ${ }^{19}$, from the same transcriptome and the sequences obtained by Romiguier et al. ${ }^{49}$. The transcriptome sequences were deposited in GenBank with the accession numbers indicated in Table 2, while those from Romiguier et al. are included in Supplementary Material. 
Table 2

Primer sequence and efficiency of the primer set for each gene

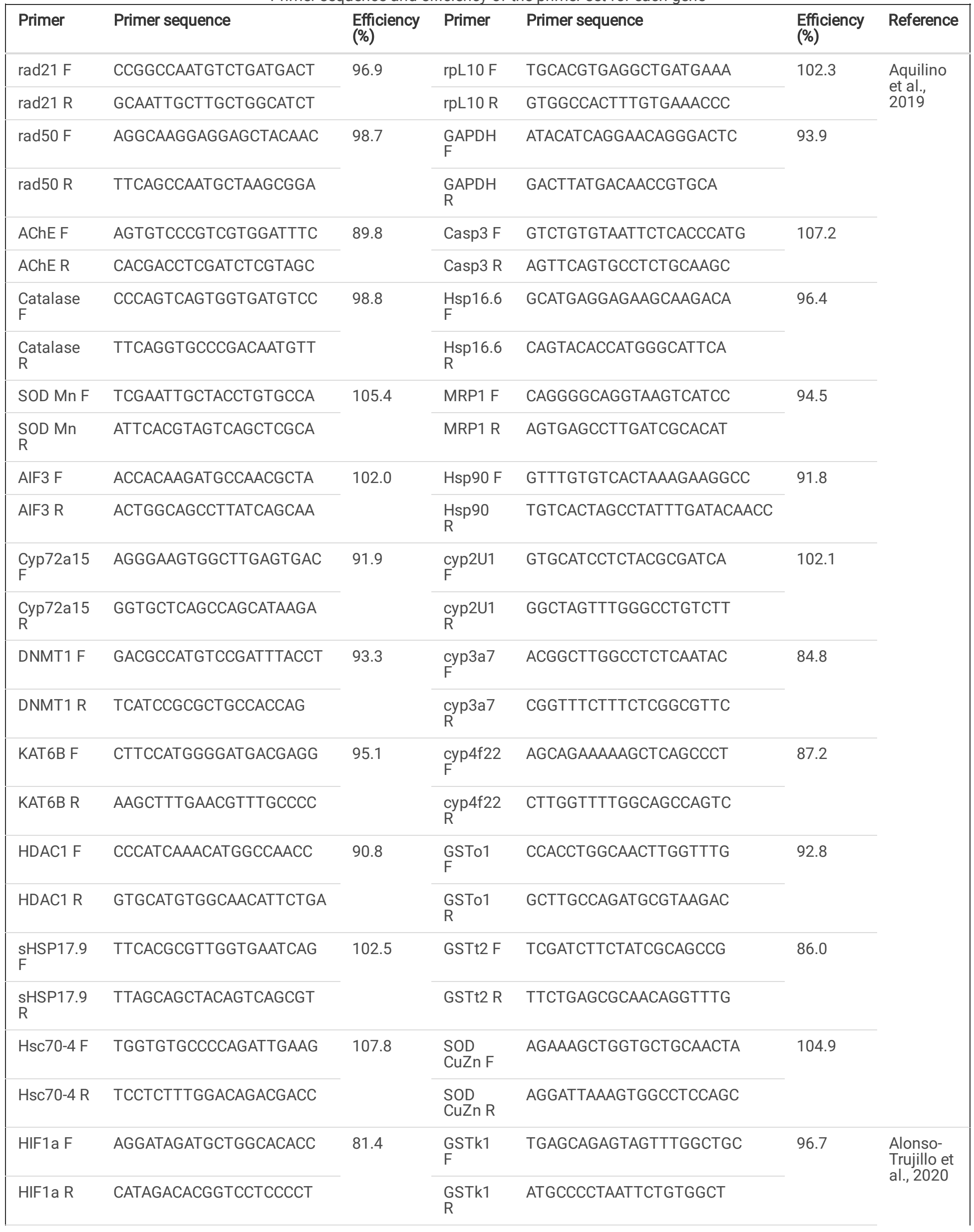




\begin{tabular}{|c|c|c|c|c|c|c|}
\hline Primer & Primer sequence & $\begin{array}{l}\text { Efficiency } \\
(\%)\end{array}$ & Primer & Primer sequence & $\begin{array}{l}\text { Efficiency } \\
(\%)\end{array}$ & Reference \\
\hline ApA F & GTGCCGGGAAAGTGATTTTAG & \multirow[t]{2}{*}{99.6} & $\begin{array}{l}\text { GSTm1 } \\
\text { F }\end{array}$ & ATTGGGCCATTAGAGGGCTT & \multirow[t]{2}{*}{93.1} & \\
\hline ApA R & CAGCCACCAGGGTCGCGA & & $\begin{array}{l}\mathrm{GSTm} 1 \\
\mathrm{R}\end{array}$ & GTTGGACCATCTCCTTGCAC & & \\
\hline PYGL F & ACTGACCCCTGCGTGTAAAG & \multirow[t]{2}{*}{104.2} & Hsp60 F & ATTGCTTATCGTGGCTGAGG & \multirow[t]{2}{*}{82.0} & \\
\hline PYGL R & TGGAGGCAGGGTTGATCTTG & & $\begin{array}{l}\text { Hsp60 } \\
\mathrm{R}\end{array}$ & TGGCAATAGCCATATCCTGC & & \\
\hline ORP8 F & GCTGGACGGACATCACTTGT & \multirow[t]{2}{*}{98.9} & Grp78 F & TGGTGGCTCAACCCGTATTC & \multirow[t]{2}{*}{96.8} & \\
\hline ORP8 R & TGGATGTCTACCACTCGGGA & & Grp78 R & ССССАСТСААAАСАССАGСТ & & \\
\hline ACT F & GAAGAGCTACGAGCTTCCCG & \multirow[t]{2}{*}{102.1} & & & & \\
\hline ACT R & CATGGATACCGGCAGACTCC & & & & & \\
\hline PFKFB2 F & AGCGCACTATCCAAACTGCT & \multirow[t]{2}{*}{110.6} & & & & \\
\hline PFKFB2 R & TCTGCAAAGTCCTGGGGGTA & & & & & \\
\hline
\end{tabular}

\section{RNA extraction}

The frozen snails were used to extract the RNA using TRIzol (Invitrogen, Germany). The manufacturer's instructions were followed. The animals were homogenized in $300 \mu \mathrm{L}$ of TRIzol, including the shell. Once the RNA was isolated, it was treated with RNAse-free DNAse for 45 minutes at $37^{\circ} \mathrm{C}$ to remove the rest of the DNA. Afterward, a phenol: chloroform extraction was performed with Phase Lock tubes (5 prime) to remove any DNAse. The RNA was precipitated and resuspended in $100 \mu \mathrm{L}$ of diethylpyrocarbonate treated water (DEPC water). After checking the integrity by agarose gel electrophoresis and the quantity by a spectrophotometer (Biophotometer, Eppendorf), the samples were stored at $-80^{\circ} \mathrm{C}$ until the next step.

\section{Reverse transcription}

The reverse transcription was performed with the M-MLV enzyme (Invitrogen, Germany). The manufacturer's instructions were followed. For each sample, $5 \mu \mathrm{g}$ of RNA were used for a final $40 \mu \mathrm{L}$ reaction. The mix was carried out with poly-dT(18) and 200 units of M-MLV. The mixture was incubated for 50 minutes at $37^{\circ} \mathrm{C}$ and stopped at $65^{\circ} \mathrm{C}$ for 15 minutes. The samples were stored at $-80^{\circ} \mathrm{C}$ until use.

\section{Real-time PCR}

The primers were poured into the wells, and a master mix of CDNA ( $0.2 \mu \mathrm{L} /$ well), $0.5 \mathrm{X}$ EvaGreen, 20 units of Taq polymerase, $0.4 \mathrm{mM}$ dNTPs, and $2 \mathrm{mM} \mathrm{Cl}_{2} \mathrm{Mg}$ was prepared. The reaction's final volume was $10 \mu \mathrm{L}$ and was performed with a CFX96 thermocycler (Bio-Rad, USA). The thermal cycling program included an initial denaturation at $95^{\circ} \mathrm{C}$ for $30 \mathrm{~s}$ followed by 40 cycles of $95^{\circ} \mathrm{C}$ denaturation for $15 \mathrm{~s}$, $58^{\circ} \mathrm{C}$ annealing for $15 \mathrm{~s}$, and $72^{\circ} \mathrm{C}$ elongation for $30 \mathrm{~s}$. Finally, a melting curve was generated to confirm the presence of a single peak. Reference genes were glyceraldehyde-3-phosphate dehydrogenase $(G A P D H)$, ribosomal protein L10 $(r p L 10)$, actin (act), and 6phosphofructo-2-kinase (PFKFB2). Because some of the genes were in low quantities, the efficiency curves cannot be prepared with the CDNA. An alternative approach was used. A PCR with the same conditions as RT-PCR for each gene was carried out, and electrophoresis was run to ensure that single products were obtained. One microliter of each gene PCR was mixed in a tube, and water was added to 50 $\mu \mathrm{L}$. From this 1:50 mixture was taken $1 \mu \mathrm{L}$ and used to obtain a 1:25000 final dilution. Then, $1 \mu \mathrm{L}$ was used to do the first concentration of the five 1:2-dilution series prepared to perform the efficiency curve. Primers and efficiencies are listed in Table 2. The RT-PCR was done running duplicate wells for each sample, and two independent replicates were used for each experiment. Bio-Rad CFX Maestro software was used to analyze and determine total mRNA levels of normalized gene expression $\left(2^{-\Delta \Delta C q}\right)$.

\section{Statistical analysis}

Statistical analysis was done using SPSS 25 (IBM, USA). Normal distribution and variance homogeneity were tested by the Shapiro-Wilk and Levene tests, respectively. Because the data was not normally distributed, they were analyzed with the nonparametric Kruskal-Wallis test with the Bonferroni correction. Statistical significance was set at $p \leq 0.05$.

\section{Declarations}




\section{Acknowledgments}

This work was supported by Programa Estatal de I+D+i Orientada a los Retos de la Sociedad (Spain), Grant RTI2018-094598-B-100 from the Ciencias y Tecnologías Medioambientales program, Ministerio de Ciencia Innovación y Universidades. M.P. received a research assistant contract from Plan Empleo Juvenil, Comunidad de Madrid (PEJ-2019-AI/AMB-12448); and P. C. received a predoctoral contract from Plan de Empleo Juvenil, Comunidad de Madrid (PEJD-2019-PRE/AMB-14815), both co-funded by Consejeria de Educación e Investigación (Comunidad de Madrid) and the European Social Fund (ESF). The authors declare that they have no conflict of interest.

\section{Author contributions (names must be given as initials)}

J-L. M-G.conceived and designed the work and wrote the manuscript text and prepared the figures 1-6, tables, and supplementary material. M. P-A. and P. C. collected the data and contributed to data analysis and figure preparation. All the authors reviewed the articles.

\section{Competing Interests Statement}

The authors declare no competing interests.

\section{References}

1. Geyer, R., Jambeck, J. R. \& Law, K. L. Production, use, and fate of all plastics ever made. Science Advances 3, e1700782 (2017).

2. Gao, D., Li, Z., Wang, H. \& Liang, H. An overview of phthalate acid ester pollution in China over the last decade: Environmental occurrence and human exposure. Science of The Total Environment 645, 1400-1409 (2018).

3. Hahladakis, J. N., Velis, C. A., Weber, R., lacovidou, E. \& Purnell, P. An overview of chemical additives present in plastics: Migration, release, fate and environmental impact during their use, disposal and recycling. Journal of Hazardous Materials 344, 179-199 (2018).

4. Das, M. T., Ghosh, P. \& Thakur, I. S. Intake estimates of phthalate esters for South Delhi population based on exposure media assessment. Environmental Pollution 189, 118-125 (2014).

5. Fromme, H. et al. Occurrence of phthalates and bisphenol A and F in the environment. Water Research 36, 1429-1438 (2002).

6. Chakraborty, P. et al. Surveillance of plasticizers, bisphenol A, steroids and caffeine in surface water of River Ganga and Sundarban wetland along the Bay of Bengal: occurrence, sources, estrogenicity screening and ecotoxicological risk assessment. Water Research 190, 116668 (2021).

7. Giuliani, A., Zuccarini, M., Cichelli, A., Khan, H. \& Reale, M. Critical Review on the Presence of Phthalates in Food and Evidence of Their Biological Impact. Int J Environ Res Public Health 17, (2020).

8. Mariana, M. \& Cairrao, E. Phthalates Implications in the Cardiovascular System. J Cardiovasc Dev Dis 7, (2020).

9. Qian, Y., Shao, H., Ying, X., Huang, W. \& Hua, Y. The Endocrine Disruption of Prenatal Phthalate Exposure in Mother and Offspring. Front Public Health 8, 366 (2020).

10. Sears, C. G. \& Braun, J. M. Phthalate Exposure, Adolescent Health, and the Need for Primary Prevention. Endocrinol Metab Clin North Am 49, 759-770 (2020).

11. Weaver, J. A. et al. Hazards of diethyl phthalate (DEP) exposure: A systematic review of animal toxicology studies. Environ Int 145, 105848 (2020).

12. Dutta, S., Haggerty, D. K., Rappolee, D. A. \& Ruden, D. M. Phthalate Exposure and Long-Term Epigenomic Consequences: A Review. Front Genet 11, 405 (2020).

13. Herrero, Ó., Planelló, R. \& Morcillo, G. The plasticizer benzyl butyl phthalate (BBP) alters the ecdysone hormone pathway, the cellular response to stress, the energy metabolism, and several detoxication mechanisms in Chironomus riparius larvae. Chemosphere 128, 266-277 (2015).

14. How, C. M., Yen, P.-L., Wei, C.-C., Li, S.-W. \& Liao, V. H.-C. Early life exposure to di(2-ethylhexyl)phthalate causes age-related declines associated with insulin/IGF-1-like signaling pathway and SKN-1 in Caenorhabditis elegans. Environ Pollut 251, 871-878 (2019).

15. Shaha, C. M. \& Pandit, R. S. Biochemical and molecular changes mediated by plasticizer diethyl phthalate in Chironomus circumdatus (bloodworms). Comp Biochem Physiol C Toxicol Pharmacol 228, 108650 (2020). 
16. Zhou, J., Chen, B. \& Cai, Z. Metabolomics-based approach for assessing the toxicity mechanisms of dibutyl phthalate to abalone (Haliotis diversicolor supertexta). Environ Sci Pollut Res Int 22, 5092-5099 (2015).

17. Zhou, J., Zhu, X.-S. \& Cai, Z.-H. Influences of DMP on the fertilization process and subsequent embryogenesis of abalone (Haliotis diversicolor supertexta) by gametes exposure. PLoS One 6, e25951 (2011).

18. Zhou, J., Cai, Z.-H. \& Xing, K.-Z. Potential mechanisms of phthalate ester embryotoxicity in the abalone Haliotis diversicolor supertexta. Environ Pollut 159, 1114-1122 (2011).

19. Aquilino, M., Sánchez-Argüello, P., Novo, M. \& Martínez-Guitarte, J.-L. Effects on tadpole snail gene expression after exposure to vinclozolin. Ecotoxicol. Environ. Saf. 170, 568-577 (2019).

20. Cheng, H., Zhang, N. \& Pati, D. Cohesin subunit RAD21: From biology to disease. Gene 758, 144966 (2020).

21. Park, Y. B. et al. Eukaryotic Rad50 Functions as A Rod-shaped Dimer. Nat Struct Mol Biol 24, 248-257 (2017).

22. Bhagat, J., Ingole, B. S. \& Singh, N. Glutathione S-transferase, catalase, superoxide dismutase, glutathione peroxidase, and lipid peroxidation as biomarkers of oxidative stress in snails: A review. ISJ-INVERT SURVIV J 13, 336-349 (2016).

23. Vinken, M. The adverse outcome pathway concept: a pragmatic tool in toxicology. Toxicology 312, 158-165 (2013).

24. Kinoshita, E., van der Linden, E., Sanchez, H. \& Wyman, C. RAD50, an SMC family member with multiple roles in DNA break repair: how does ATP affect function? Chromosome Res 17, 277-288 (2009).

25. Li, Y., Wang, Z., Zhao, Z. \& Cui, Y. iTRAQ-based proteome profiling of hyposaline responses in zygotes of the Pacific oyster Crassostrea gigas. Comp Biochem Physiol Part D Genomics Proteomics 30, 14-24 (2019).

26. Domingues, I., Agra, A. R., Monaghan, K., Soares, A. M. V. M. \& Nogueira, A. J. A. Cholinesterase and glutathione-S-transferase activities in freshwater invertebrates as biomarkers to assess pesticide contamination. Environmental Toxicology and Chemistry 29 , 5-18 (2010).

27. Ortiz de Montellano, Paul R. (Ed.). Cytochrome P450: Structure, Mechanism, and Biochemistry. (Springer US, 2005). doi:10.1007/b139087.

28. Graham, A. M. \& Presnell, J. S. Hypoxia Inducible Factor (HIF) transcription factor family expansion, diversification, divergence and selection in eukaryotes. PLoS One 12, e0179545 (2017).

29. Skinner, M. K. \& Anway, M. D. Epigenetic transgenerational actions of vinclozolin on the development of disease and cancer. Crit Rev Oncog 13, 75-82 (2007).

30. Vandegehuchte, M. B., Lemière, F., Vanhaecke, L., Vanden Berghe, W. \& Janssen, C. R. Direct and transgenerational impact on Daphnia magna of chemicals with a known effect on DNA methylation. Comp. Biochem. Physiol. C Toxicol. Pharmacol. 151, 278-285 (2010).

31. Xin, F., Susiarjo, M. \& Bartolomei, M. S. Multigenerational and transgenerational effects of endocrine disrupting chemicals: A role for altered epigenetic regulation? Semin. Cell Dev. Biol. 43, 66-75 (2015).

32. Li, J., Cai, Y., Shi, Y., Mou, S. \& Jiang, G. Analysis of phthalates via HPLC-UV in environmental water samples after concentration by solid-phase extraction using ionic liquid mixed hemimicelles. Talanta 74, 498-504 (2008).

33. Net, S., Sempéré, R., Delmont, A., Paluselli, A. \& Ouddane, B. Occurrence, Fate, Behavior and Ecotoxicological State of Phthalates in Different Environmental Matrices. Environ. Sci. Technol. 49, 4019-4035 (2015).

34. Avilès, A. et al. Effects of DEHP on the ecdysteroid pathway, sexual behavior and offspring of the moth Spodoptera littoralis. Hormones and Behavior 125, 104808 (2020).

35. Chen, M.-Y. et al. Transgenerational impact of DEHP on body weight of Drosophila. Chemosphere 221, 493-499 (2019).

36. Cuenca, L. et al. Environmentally-relevant exposure to diethylhexyl phthalate (DEHP) alters regulation of double-strand break formation and crossover designation leading to germline dysfunction in Caenorhabditis elegans. PLOS Genetics 16, e1008529 (2020).

37. Pradhan, A., Olsson, P.-E. \& Jass, J. Di(2-ethylhexyl) phthalate and diethyl phthalate disrupt lipid metabolism, reduce fecundity and shortens lifespan of Caenorhabditis elegans. Chemosphere 190, 375-382 (2018).

38. Liu, Y. et al. Toxicity of seven phthalate esters to embryonic development of the abalone Haliotis diversicolor supertexta. Ecotoxicology 18, 293-303 (2009).

39. Lu, Y. et al. Characterisation of immune-related gene expression in clam (Venerupis philippinarum) under exposure to di(2-ethylhexyl) phthalate. Fish Shellfish Immuno/ 34, 142-146 (2013).

40. Xiang, N., Zhao, C., Diao, X., Han, Q. \& Zhou, H. Dynamic responses of antioxidant enzymes in pearl oyster Pinctada martensii exposed to di(2-ethylhexyl) phthalate (DEHP). Environ Toxicol Pharmacol 54, 184-190 (2017).

Page 10/16 
41. Alam, M. S. \& Kurohmaru, M. Butylbenzyl phthalate induces spermatogenic cell apoptosis in prepubertal rats. Tissue Cell 48, 35-42 (2016).

42. Dos Santos Morais, G. et al. Genotoxic, metabolic, and biological responses of Chironomus sancticaroli Strixino \& Strixino, 1981 (Diptera: Chironomidae) after exposure to BBP. Sci Total Environ 715, 136937 (2020).

43. Song, P. et al. Phthalate induced oxidative stress and DNA damage in earthworms (Eisenia fetida). Environ Int 129, 10-17 (2019).

44. Planelló, R., Herrero, O., Martínez-Guitarte, J. L. \& Morcillo, G. Comparative effects of butyl benzyl phthalate (BBP) and di(2-ethylhexyl) phthalate (DEHP) on the aquatic larvae of Chironomus riparius based on gene expression assays related to the endocrine system, the stress response and ribosomes. Aquat. Toxicol. 105, 62-70 (2011).

45. Oehlmann, J. et al. A critical analysis of the biological impacts of plasticizers on wildlife. Philos Trans R Soc Lond B Biol Sci 364 2047-2062 (2009).

46. Agency, E. C. Support document to the opinion of the member state committee for identification of benzyl butyl phthalate (bbp) as a substance of very high concern because of its endocrine disrupting properties which cause probable serious effects to human health and the environment which give rise to an equivalent level of concern to those of cmr1 and pbt/vpvb2 substances. Available online at https://echa.europa.eu/documents/10162/21833221/svhc_msc_opinion_support_document_bbp_20141211_en.pdf/c5e7a581-db154e09-8be9-37d42c5409d8. (2014).

47. Li, J. et al. Effects of butyl benzyl phthalate exposure on Daphnia magna growth, reproduction, embryonic development and transcriptomic responses. J Hazard Mater 404, 124030 (2021).

48. Alonso-Trujillo, M., Muñiz-González, A.-B. \& Martínez-Guitarte, J.-L. Endosulfan exposure alters transcription of genes involved in the detoxification and stress responses in Physella acuta. Scientific Reports 10, 7847 (2020).

49. Romiguier, J. et al. Comparative population genomics in animals uncovers the determinants of genetic diversity. Nature $\mathbf{5 1 5}$, 261-263 (2014).

\section{Figures}

\section{Figure 1}

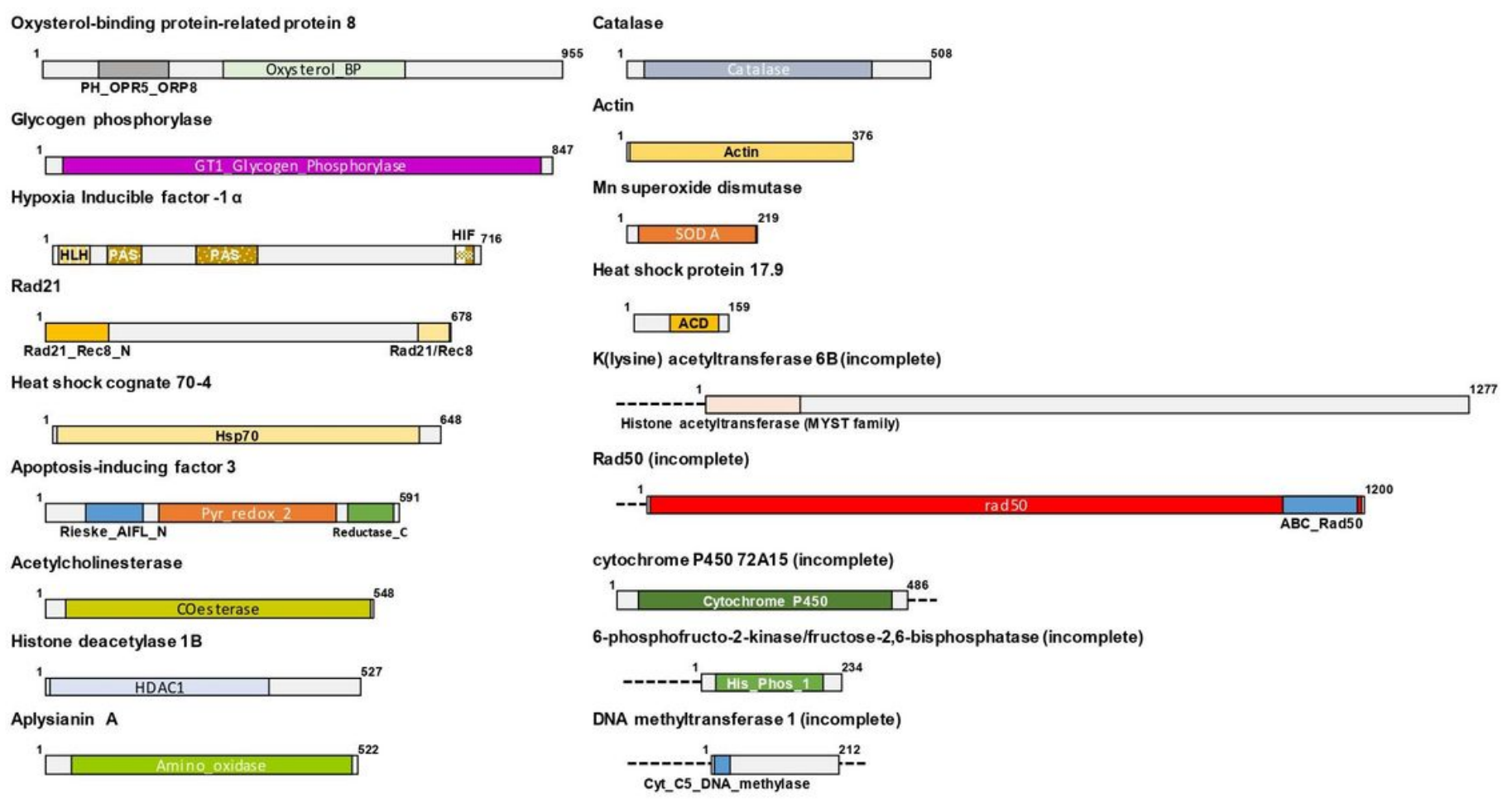

Figure 1 
Structure and conserved domains of the identified Physella acuta proteins. Each protein corresponds to an open reading frame from the sequences used in the study. The proteins are shown with the different motifs that characterize them. The domains are defined according to the CCD functional classification of proteins. Some of the genes were not complete, and the discontinuous line indicates the unknown up- and down-stream regions.

\section{Figure 2}
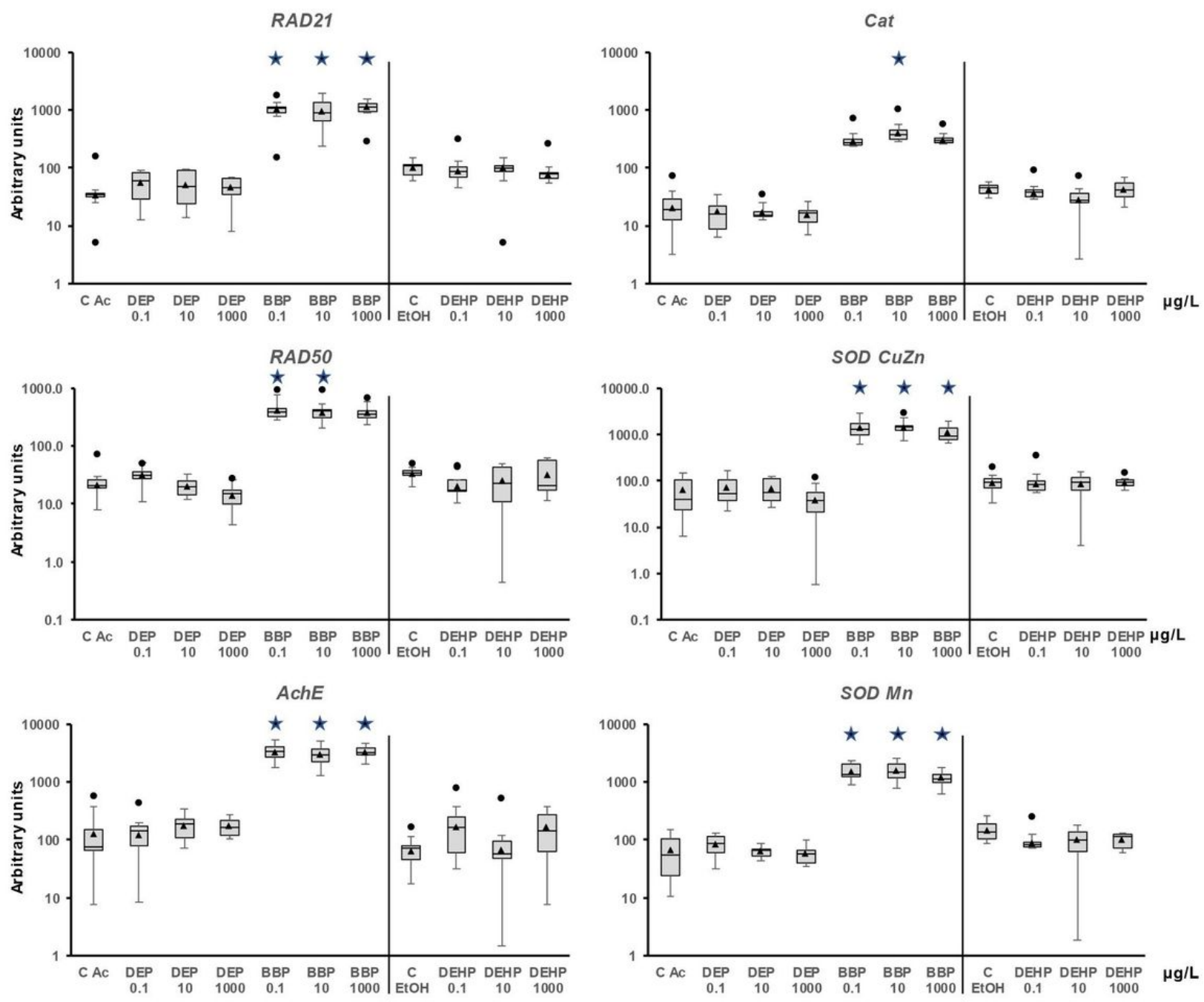

\section{Figure 2}

Transcript levels of DNA repairing mechanisms (RAD21 and RAD50), nervous system (AChE), and oxidative stress (Cat, SOD CuZn, and SOD Mn) genes in Physella acuta adults after in vivo exposure to diethyl phthalate (DEP), benzyl butyl phthalate (BBP), and bis-(2ethylhexyl) phthalate (DEHP) for seven days at $19{ }^{\circ} \mathrm{C}$. Transcriptional activity was quantified by RT-PCR using rpL10, Act, PFKFB2, and GAPDH as reference genes. The comparison was performed with the solvent-exposed controls. Whisker boxes are shown. Each box corresponds to nine individuals. The median is indicated by the horizontal line within the box, and the 25th and 75th percentiles are indicated by the boundaries of the box. The highest and lowest results are represented by the whiskers. The small triangle inside the box denotes the mean, and the outliers are shown (circles). Significant differences to respective controls (asterisk) are indicated $(p<0.05)$. 


\section{Figure 3}
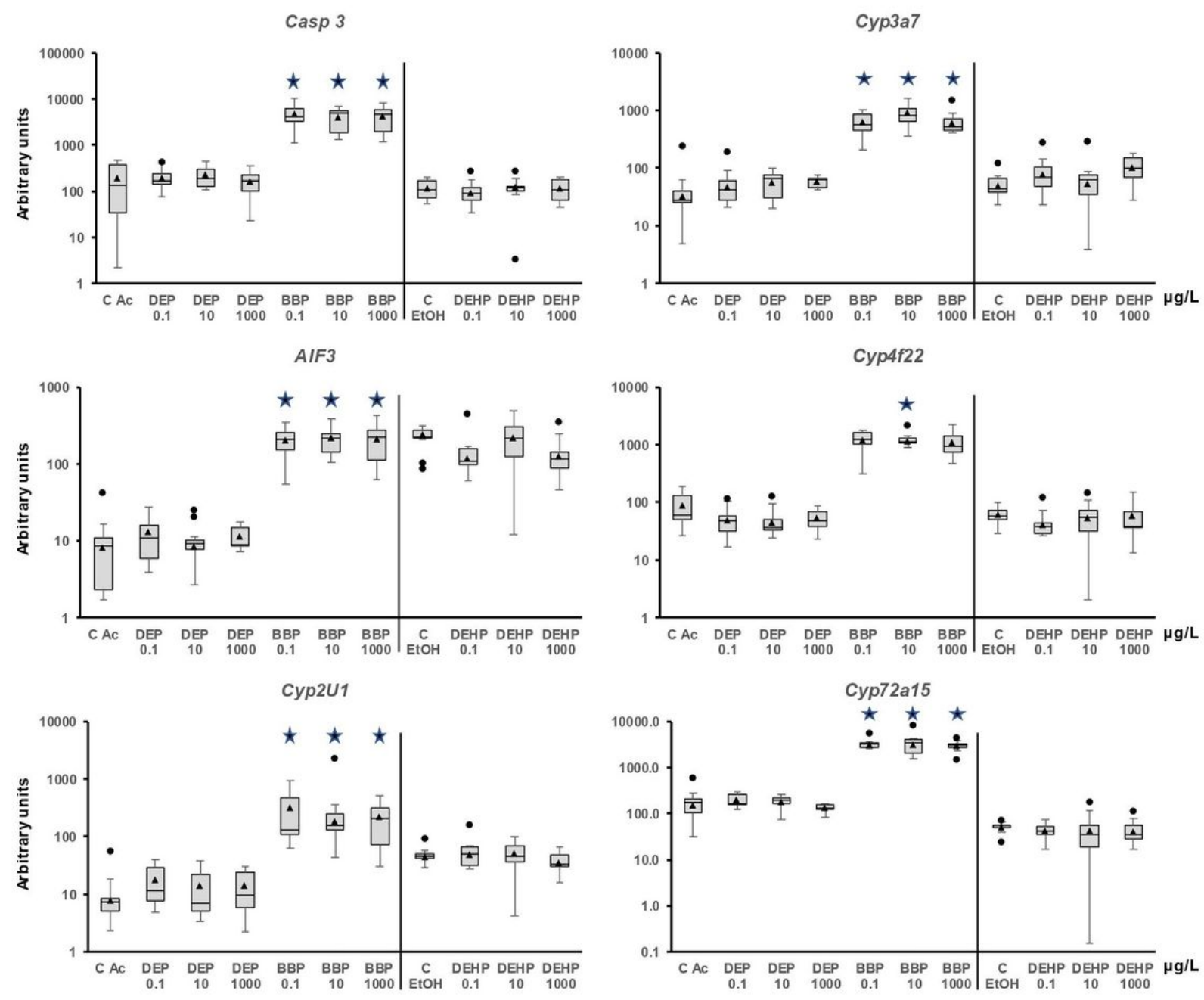

\section{Figure 3}

Transcriptional activity of apoptosis (Casp3 and AIF3) and phase I related genes (Cyp2u1, Cyp3a7, Cyp4f22, and Cyp72a15) in adult Physella acuta after in vivo exposure to three phthalates at $19{ }^{\circ} \mathrm{C}$ for seven days. Levels of mRNA were normalized using $\mathrm{rpL} 10, \mathrm{Act}$, PFKFB2, and GAPDH as reference genes. The comparison was performed with the solvent-exposed controls. Whisker boxes are shown. The $\mathrm{n}$ for each box is nine. The median is indicated by the horizontal line within the box, and the 25th and 75th percentiles are indicated by the boundaries of the box. The highest and lowest results are represented by the whiskers. The small triangle inside the box denotes the mean, and the outliers are shown (circles). Significant differences to respective controls (asterisk) are indicated $(p<0.05)$. 


\section{Figure 4}
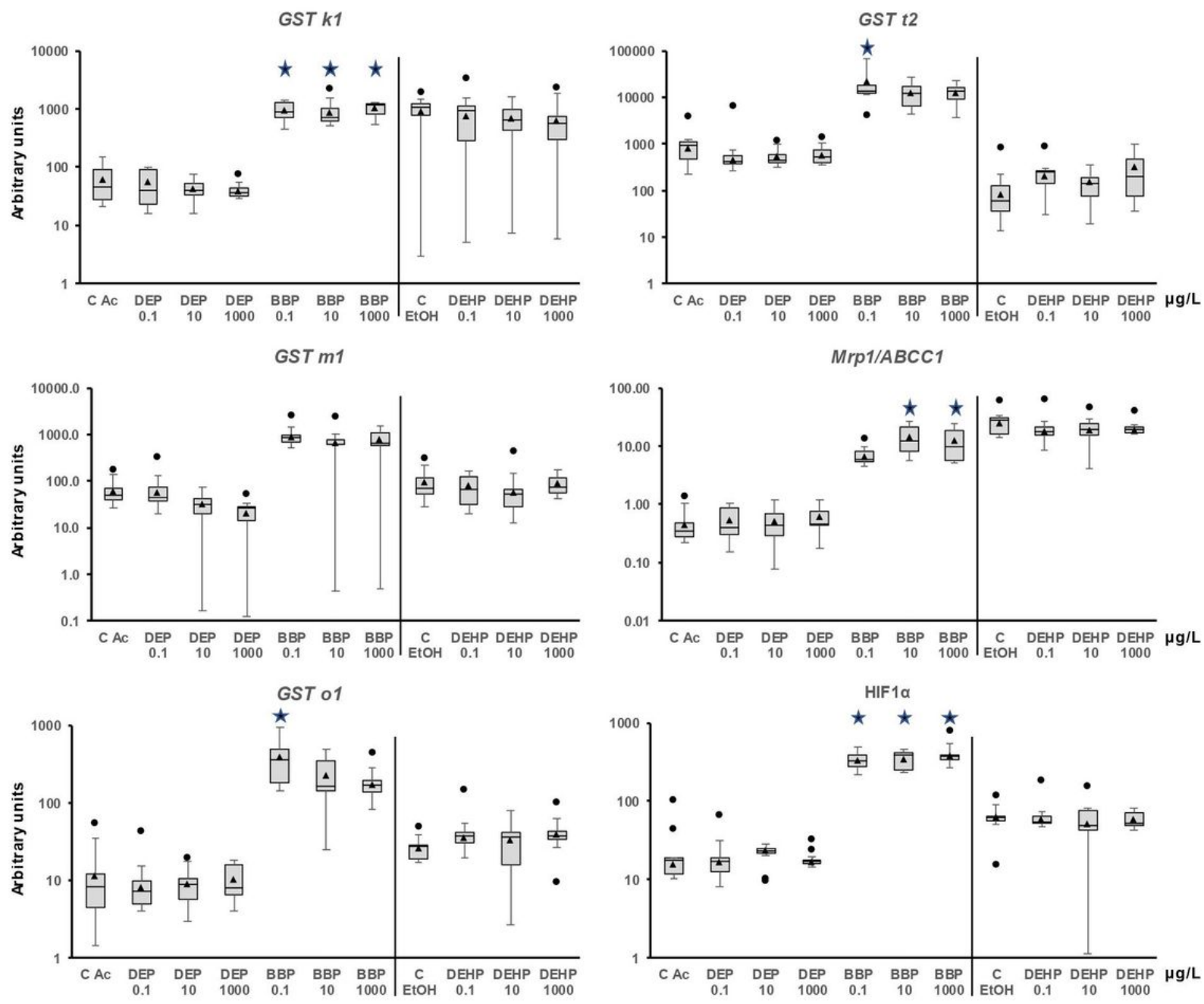

\section{Figure 4}

The mRNA levels of genes related to phase II (GSTk1, GSTm1, GSTo1, and GSTt2) and phase III (MRP1/ABCC1) of detoxification and hypoxia (HIF1a) in adult Physella acuta after in vivo exposure to DEP, BBP, and DEHP at $19{ }^{\circ} \mathrm{C}$ for seven days. As reference genes for normalization, rpL10, Act, PFKFB2, and GAPDH were used. The comparison was performed with the solvent-exposed controls. Whisker boxes are shown. The $\mathrm{n}$ for each box is nine. The median is indicated by the horizontal line within the box, and the 25th and 75th percentiles are indicated by the boundaries of the box. The highest and lowest results are represented by the whiskers. The small triangle inside the box denotes the mean, and the outliers are shown (circles). Significant differences to respective controls (asterisk) are indicated $(p<0.05)$. 
Figure 5
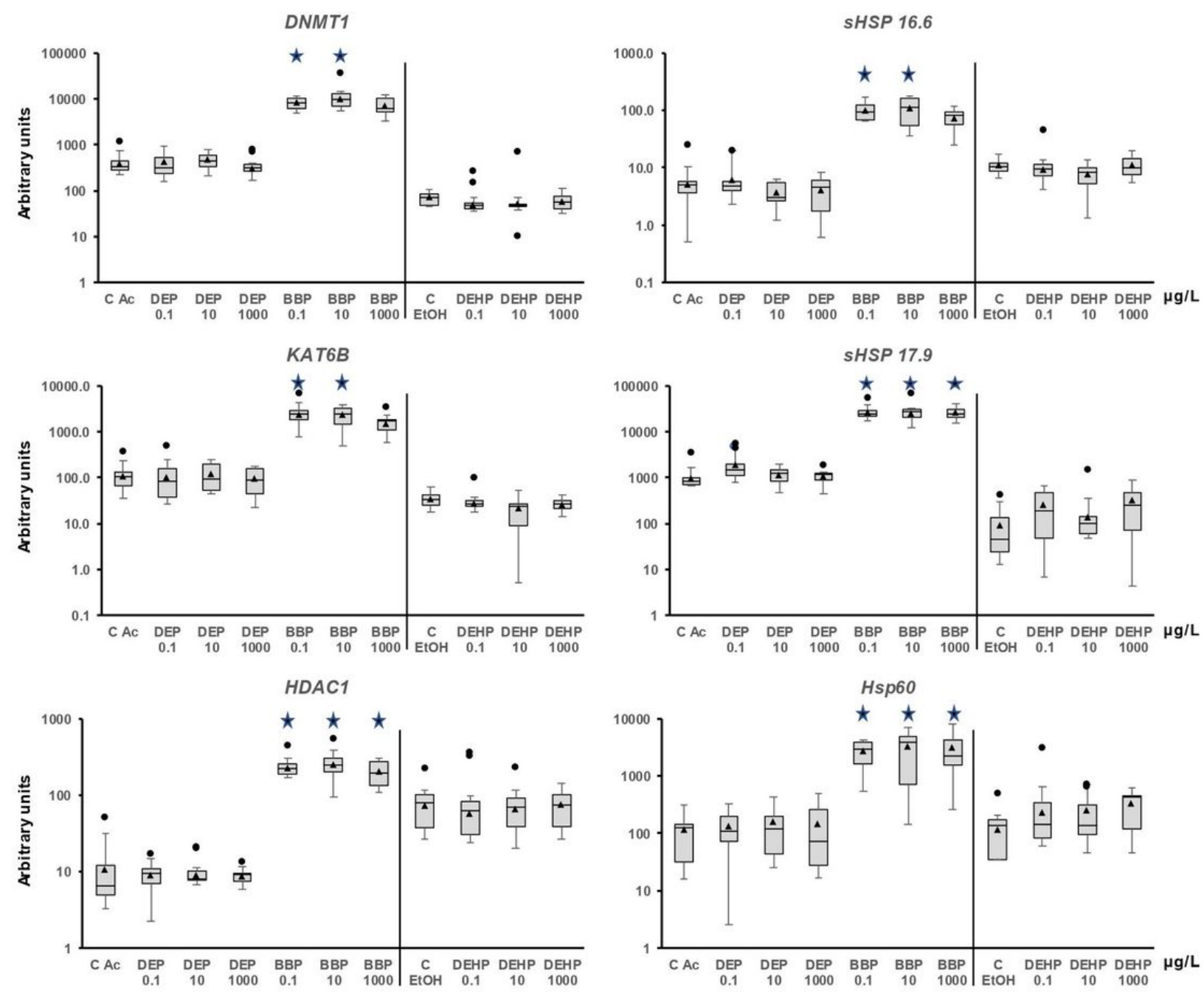

\section{Figure 5}

Response of the genes involved in epigenetic regulation (DNMT1, KAT6B, and HDAC1) and stress response (sHsp 16.6, sHsp 17.9, and Hsp60) in adult Physella acuta after in vivo exposure to the phthalates DEP, BBP, and DEHP at $19{ }^{\circ} \mathrm{C}$ for seven days. Normalization was performed by using rpL10, Act, PFKFB2, and GAPDH as reference genes. Treated animals were compared to solvent-exposed controls. Whisker boxes are shown. Each box corresponds to nine individuals. The horizontal line within the box indicates the median, and the box's boundaries indicate the 25th and 75th percentiles. The whiskers represent the highest and lowest results. The small triangle inside the box denotes the mean, and the outliers are shown (circles). Significant differences to respective controls (asterisk) are indicated ( $p<0.05$ ). 


\section{Figure 6}
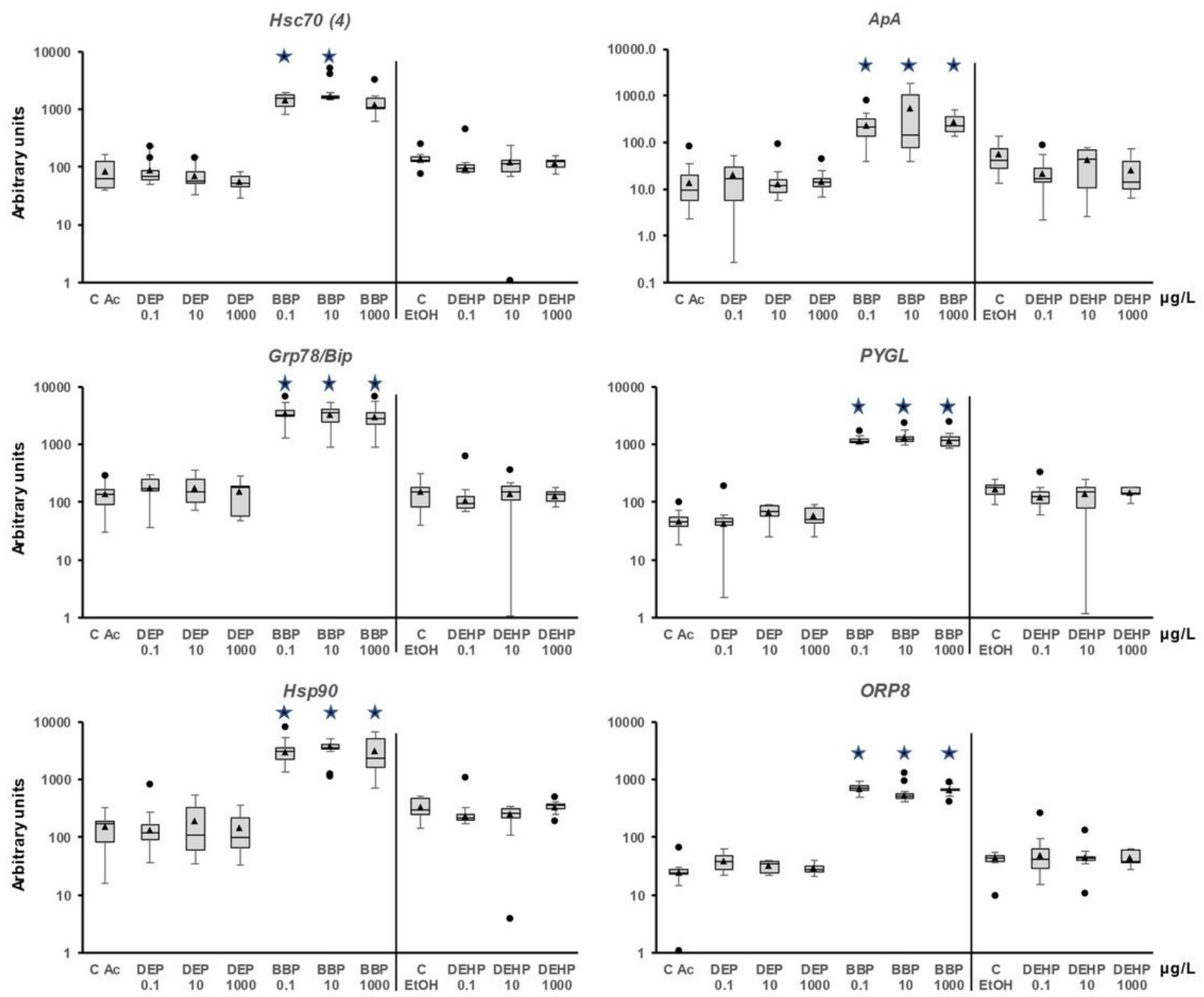

\section{Figure 6}

Modulation of genes related to stress (Hsc70 (4), Grp78/BiP, and Hsp90), immune system (ApA), energy metabolism (PYGL), and lipid transportation (ORP8) in adult Physella acuta after in vivo exposure to DEP, BBP, and DEHP at $19{ }^{\circ} \mathrm{C}$ for seven days. Levels of mRNA were normalized using rpL10, Act, PFKFB2, and GAPDH as reference genes. Treatments were compared to respective solvent-exposed controls. Whisker boxes are shown. The $\mathrm{n}$ for each box is nine. The median is indicated by the horizontal line within the box, and the 25 th and 75 th percentiles are indicated by the boundaries of the box. The highest and lowest results are represented by the whiskers. The small triangle inside the box denotes the mean and the outliers are shown (circles). Significant differences to respective controls (asterisk) are indicated $(p<0.05)$.

\section{Supplementary Files}

This is a list of supplementary files associated with this preprint. Click to download.

- Supplementarymaterial.docx 